\title{
A "VOCAÇÃO" EXTRATIVISTA LATINO-AMERICANA E OS MOVIMENTOS SOCIAIS
}

\author{
Guillermo Alfredo Johnson \\ Universidade Federal da Grande Dourados (UFGD) \\ Marcos Antônio da Silva \\ Universidade Federal da Grande Dourados (UFGD)
}

\begin{abstract}
A "VOCAÇÃO” EXTRATIVISTA LATINO-AMERICANA E OS MOVIMENTOS SOCIAIS
Resumo: O artigo aponta que uma das questões vinculadas à inserção dos países latino-americanos no sistema mundial interfere significativamente na reprodução do capital e, ao mesmo tempo, ergue-se em um dos principais aspectos da intensidade dos movimentos sociais: o caráter persistentemente extrativista das nossas economias. Nesta senda, a atuação do Estado, com viés desenvolvimentista pautado pelo financiamento e fortalecimento do setor privado, tem favorecido o agronegócio (freando a reforma agrária e as reivindicações dos quilombolas e indígenas), executando uma agenda de ampliação da infraestrutura (portos, hidrelétricas, estradas e políticas energéticas, para citar alguns) e facilitado à extração de minérios ao sul do Rio Bravo. Dimensões desses elementos têm provocado a reação das populações desde os lugarejos mais recônditos da Nossa América, com mobilizações populares, frequentemente isoladas pelos meios de comunicação de massas, e com o desmonte da virulência daqueles mais consolidados (como o MST no caso brasileiro). Ao mesmo tempo, no caso das grandes obras de infraestrutura, registra-se a proteção estatal ao regime precário de trabalho, com vistas a privilegiar esses setores estratégicos para o grande capital. Tendo em vista a dispersão geográfica desses movimentos sociais, assim como a desarticulação que se observa daqueles que não pouco tempo atrás se confrontavam com as políticas estatais, torna-se necessário pensar as possibilidades de unificação dessa diversidade de reivindicações aliadas às demandas dos trabalhadores.
\end{abstract}

Palavras-chave: Estado, extrativismo, movimentos sociais.

\section{THE LATIN AMERICAN EXTRACTIVE "VOCATION" AND THE SOCIAL MOVEMENTS}

Abstract: The article points that one of the issues related to the integration of Latin American countries in the world system significantly interferes with the reproduction of capital and, at the same time, rise up in one of the main aspects of the intensity of social movements: the character of our economies persistently extractive. In this vein, the role of the State, with a bias guided by a development ruled in funding and strengthening the private sector, has consistently favored agribusiness (braking the agrarian reform and the demands of the quilombolas and indigenous people), performing an agenda for expansion of infrastructure (ports, hydroelectric plants, roads and energy policies, to name a few) and facilitated the extraction of ores from south of the Rio Bravo. The extent of these elements has triggered the reaction of the people from the most remote villages of Our America, with popular mobilizations, often isolated by mass communication, and with the dismantling of virulence of those more established (as in the Brazilian MST). At the same time, in the case of large infrastructure projects, it was possible to observe the state protection for precarious work arrangements, in order to privilege these strategic sectors for great capital. In view of the geographic dispersion of these social movements, as well as the disarticulation is observed among those that recently clashed with state policies, it is necessary to consider the possibilities of unifying this diversity of claims allied with the demands of the workers.

Keywords: State, extractivism, social movements. 


\section{INTRODUÇÃO}

O padrão de inserção histórica dos países da América Latina, ainda que tenhamos vivenciado transformações desde a sua inserção no sistema mundial, secaracterizapelapersistentesubordinação. As decisões em torno das questões políticas, econômicas e ambientais na contemporaneidade emanam do G8, eminentemente dos EUA, que detém a maior máquina de guerra e as rédeas da financeirização e da economia mundial.

O fornecimento de matérias primas para o centro do sistema internacional não é uma vocação recente dos países latino-americanos. Mas, a partir das últimas quatro décadas foi possível verificar o ressurgimento da exportação de produtos primários como principal pauta de inserção no mercado mundial, configurando uma reprimarização das economias latino-americanas. Essa conjuntura acontece no bojo de uma reconfiguração do papel do Estado e na necessidade premente dos movimentos sociais de demonstração do seu descontentamento ante essa realidade. Os aspectos assinalados serão debatidos sucintamente a seguir.

\section{O ESTADO NA AMÉRICA LATINA E OS NOVOS EXTRATIVISMOS}

Possivelmente, uma das manifestações mais esclarecedoras dessa relação de dependência no sistema internacional pode ser observada a partir da ótica da divisão internacional do trabalho. Nesta distribuição de papéis os países latinos da América experimentaram espasmos industriais, no segundo quartil e nos anos 70 do século passado - sem dúvida que com marcada desigualdade na intensidade e na distribuição geopolítica -, caracterizada por fábricas filiais de empresas transnacionais pautadas pela transferência de riquezas da periferia para o centro do sistema através da superexploração dos trabalhadores latino-americanos (SALAMA, 2001; MARINI, 2000; SOTELO VALENCIA, 2005). Simultaneamente, em vários países da região foram erguidos parques industriais estatais, com vistas à substituição de importações, que têm servido de plataforma para consolidação da inserção subordinada na produção industrial internacional, na medida em que não se avançara nesse processo de consolidar de forma autônoma o processamento de mercadorias em níveis demandados pelo mercado, senão que servira de plataforma para consolidação de um padrão de industrialização controlado pelos países centrais, ao mesmo tempo em que se observa perene defasagem de criação e incorporação sociotécnica da produção intelectual, o qual repercute em baixa produtividade alimentando o círculo vicioso da exploração intensiva da mão de obra barata da periferia.

Assim, aos países ao sul do Rio Bravo coube fornecer matérias primas no ritmo e intensidade marcados pelos ciclos de expansão e depressão vivenciadas desde o mercantilismo. A questão territorial, a luta pela terra, local de sobrevivência dos pobres e de enriquecimento das oligarquias terratenentes tem sido a arena que dinamiza as lutas sociais. A concentração fundiária expulsa populações autóctones, quilombolas, os trabalhadores e as suas famílias das áreas rurais na pugna pelo aumento de produtividade para auferir lucros no mercado internacional. Em diversos momentos observam-se situações em que a pecuária e a agricultura revezamse no destaque pela produção de alimentos, ao mesmo tempo em que, em nível macro, a importância geopolítica, a escolha da variedade predominante e a distribuição territorial da produção deslocam-se ao sabor dos mercados internacionais.

Outro componente importante na recente onda do extrativismo na América Latina consiste na mineração - no âmbito desta consideramos a exploração do petróleo. Essa atividade tem avançado de forma significativa nos últimos anos, apresenta uma projeção de maior número de locais de exploração, sendo que a história dessa atividade na América Latina está relacionada com a espoliação e morte de populações significativas - só para retomar um exemplo paradigmático é interessante lembrar a exploração das minas de cobre em Potosí, Bolívia, mais intensiva no século XVIII. As características incisivas de intervenção nos ambientes frequentemente mais retirados do trânsito das grandes cidades têm isolado populações autóctones ante a repressão estatal e da expansão da exploração da terra por empresas transnacionais. Neste setor econômico o papel do Estado tem sido também decisivo, pois com frequência os grandes empreendimentos e investimentos demandados pela exploração mineira são financiados direta ou indiretamente por recursos estatais. $O$ argumento recorrente aproxima-se do discurso do desenvolvimento local e da oferta de empregos como sinônimos de conferir bem-estar às populações; curiosamente, também se mencionam discursos sobre preservação ambiental decorrentes desta atividade, sendo que as evidências têm demonstrado que após o fim do período intensivo de mineração o que se observa são mazelas sociais, econômicas e ambientais (DICK; JORGENSEN, 2011).

A expansão da dimensão territorial tomada pela atividade agrícola no Brasil, Argentina e países de Centro-América, principalmente, tem aumentado significativamente nos últimos anos, embalados pelo crescente preço das commodities. O papel do Estado nessa política de ocupação territorial é decisivo, pois, frequentemente, desde a aquisição das terras (até na forma de grilagem ${ }^{1}$ ) até o financiamento periódico da produção e comercialização os governos têm fornecido de forma monopólica. A pecuária também se beneficia dessas políticas estatais, mas não experimenta o 
ritmo do crescimento observado pela soja e a cana de açúcar, por exemplo, no Brasil (RAZUMOVSKIY, 2008-2009). No que se refere à mineração, os Estados têm investido significativamente - do México à Argentina e Chile - para que essa atividade extrativa usufrua dos recursos e da legislação que considerar necessárias, fortalecendo socialmente a necessidade de distribuição - desigual - de riqueza a partir desses empreendimentos de gestão privada (marca registrada da intervenção estatal sob o neoliberalismo).

\section{MOVIMENTOS SOCIAIS E ESTADOS}

O padrão de desenvolvimento adotado pelos países latino-americanos - considerando entre estes, com as suas particularidades, aqueles considerados progressistas ou de esquerda, tem intensificado a exploração extrativista, aumentando as terras inseridas na dinâmica espoliativa do capitalismo contemporâneo, seja através da mineração quanto pelo agronegócio. A renovação da promessa clássica de uma teoria da modernização (conservadora), de aumento do PIB como forma de desenvolvimento econômico está na ordem do dia.

A denominada reprimarização dos países latino-americanos relaciona-se com as políticas estatais advindas dos setores que executam as políticas governamentais. Nesse sentido, no início do presente século temos observado uma profusão de governos com forte apoio popular, conduzidos ao poder estatal com a intenção de reverter a dinâmica neoliberal. Mas, o que temos verificado, contradizendo os discursos multitudinários, é que o setor financeiro e o empresariado transnacional, assim como também um punhado de nacionais, têm sido beneficiários diretos dos financiamentos e desonerações fiscais, dando forma a um padrão de desenvolvimento que privilegia a ideia de que o investimento externo gera emprego e traz o crescimento econômico, que por sua vez vai derramar pelo restante da sociedade o ansiado bemestar social (tese até a atualidade não comprovada).

Outro argumento para fortalecer a dilapidação dos bens naturais latino-americanos radica-se no discurso de que as rendas provindas dessas novas fontes de riquezas terão como objetivo investimentos maciços na educação e/ou na saúde. Ambos os argumentos apresentados fortalecem a necessidade, consensual nas sociedades desiguais latinoamericanas, de um aprimoramento na distribuição de rendas, tendentes a melhoria nas condições de vida da população. Esses discursos estão distantes de acontecer, ainda mais, de solucionar os problemas que as nossas sociedades vivenciam. Incluso porque localizando a região no sistema internacional verifica-se que as empresas que usufruem das riquezas minerais são canadenses, estadunidenses ou de países europeus, o que historicamente configura padrões recolonizadores; no que tange ao agronegócio, a sua estrutura baseia-se no latifúndio, nas sementes transgênicas, na mecanização excludente de utilização massiva de trabalhadores e na commoditização exportadora da produção, redundando em intensa concentração de riqueza. 0 Estado arrecada pequenas parcelas dessa produção espoliativa, ainda assim, pelo paradigma neoliberal vigente as suas políticas sociais, no geral, atuam compensatoriamente às atividades do mercado, este fornecedor preponderante das condições sociais de vida (GUDYNAS, 2012).

Os governos latino-americanos, premidos pela lógica de balanços positivos dos saldos comerciais e pelos superávits primários, fortalecem os setores extrativistas. Dentre as escassas tentativas, nos últimos anos, de controlar as atividades do agronegócio a partir dos governos, o episódio mais conhecido possivelmente seja o da Argentina entre 2009 e 2010, que buscou aumentar a taxação da produção agropecuária, polarizando a sociedade, mas voltando atrás logo depois. Mas após essas tentativas dos governos da região, o argentino inclusive, a relação com esses setores tem sido de proteção econômica, com isenções e incentivos diversos.

A política mais frequente dos governos da região tem sido o de exercer contundente controle social (JOHNSON, 2010) sobre os movimentos sociais. Desdobrando a ideia desse controle social estatal - no aspecto que poderia ser denominado de construção do consenso ou da coesão social podem ser sucintamente referenciadas as políticas sociais compensatórias (a modo do Programa Bolsa Família no Brasil) até as modalidades de cooptação de lideranças, incorporando-as nas instituições estatais, como mecanismo de fortalecimento da legitimidade. Essa modalidade de exercício do poder estatal reproduz e renova a promessa por uma sociedade igualitária sem transformações estruturais. Num polo complementar à manutenção da ordem em curso - no componente coercitivo verifica-se a eliminação de lideranças (não pelo Estado, senão contando com a impunidade dos executores), a judicialização da protesta popular/ sindical e a utilização ostensiva de uma diversidade de forças policiais para reprimir os movimentos sociais que possam questionar a viabilidade dos empreendimentos extrativistas.

Ainda que a partir do Estado e os diversos setores das classes dominantes sistematicamente se busque conter, pelo consenso ou a coerção, os movimentos sociais que - difusa ou explicitamente - demandam por uma sociedade igualitária na apropriação da riqueza, temos verificado aumento significativo de mobilizações e manifestações que questionam o status quo. Desde o início do presente século temos vivenciado movimentos sociais que contribuíram para questionar a legitimidade do poder estatal e a desigualdade econômico-social, 
entre os quais podemos destacar: os piqueteros na Argentina; os estudantes no Chile; as organizações e manifestações indígenas na Bolívia e Equador; as mobilizações na Venezuela como mecanismo para sustentar o governo; as mobilizações recentes no Brasil, para citar algumas - ainda que a heterogeneidade dessa enumeração não obedeça a alguma categorização ou hierarquia. Temos assistido a uma onda intensa de protestos no último período que vai do micro ao macro, permitindo se pensar nos últimos tempos articulações internacionais dos movimentos sociais como forma de fazer frente ao processo intenso de internacionalização do capital a exemplo da Via Campesina. Assim, ao pensar nos movimentos sociais incluímos um espectro amplo, que vai de associações vizinhais até perspectivas cada vez mais abrangentes de transformação da organização social. A necessidade de uma atuação mais persistente e ampla do Estado na tentativa de manter a protesta social nos limites do arcabouço institucional é a resposta à dimensão do descontentamento que as organizações e os movimentos sociais têm protagonizado nas ruas e no campo.

\section{CONCLUSÃO}

Opadrãodedesenvolvimento dos países latinoamericanos na contemporaneidade fundamenta-se cada vez mais na exploração intensiva dos recursos naturais, denominado como neoextrativismo. Nesse paradigma de inserção internacional a exploração dos produtos primários é estratégica para os governos. A sua exploração privada, pautada pelo neoliberalismo, torna o Estado indutor e protetor desses empreendimentos extrativos. Assim, o agronegócio, as explorações petrolíferas e mineiras adquirem importância decisiva na política estatal, fazendo com que as oligarquias vinculadas tornemse interlocutores privilegiados.

Neste contexto, o discurso pela diversidade social e o multiculturalismo parece comprometido pela soberania dos mercados. As populações autóctones (a denominada questão indígena), as questões étnicorraciais (os quilombolas) e 0 campesinato, nas diversas investidas pela terra tendem a enfrentar a intransigência estatal. Os espaços viáveis de atendimento a demandas destes setores radicam nas variações que as políticas sociais compensatórias podem lhes oferecer.

$\mathrm{Na}$ conjuntura em curso os movimentos sociais decorrentes dessa investida do capital em terras latino-americanas encontram-se fragmentados, pois parecem ainda embrionárias as redes ou políticas de unificação que permitam torná-las caudatárias da construção de uma alternativa a essa dinâmica de aprofundamento da mundialização financeira. É possível, neste cenário, com as sucintas considerações esboçadas, considerar que estamos ante uma postura defensiva por parte das populações diretamente afetadas e os movimentos sociais. Nesse sentido, é necessário apontar a construção de pautas unificadas entre os trabalhadores e explorados da cidade e do campo, entre estes nomeadamente os sem-terra, as comunidades indígenas e quilombolas.

\section{REFERÊNCIAS}

BORRAS Jr, S. M. et al. Land grabbing and global capitalist accumulation: key features. Latin America, Canadian Journal of Development Studies/Revue canadienne d'études du développement, [S. L.], v. 33, n. 4, p. 402-416, 2012.

DICK, C.; JORGENSEN, A. Capital movements and environmental harms. Journal of World-Systems Research, Washington, DC, v. XVII, n. 2, p. 482497, 2011.

GUDYNAS, E. Estado compensador y nuevos extractivismos: las ambivalencias del progresismo sudamericano. Nueva Sociedad, Buenos Aires, n. 237, ene./feb. 2012. Disponível em: <www.nuso. org>. Acesso em: 3 jul. 2013.

JOHNSON, G. A. As recentes transformações do controle social estatal. REDD - Revista de Espaços de Diálogo e Desconexão, Araraquara, v. 3, n. 1, jul./dez. 2010.

MARINI, R. M. Dialética da Dependência. Petrópolis, RJ: Vozes; Buenos Aires: CLACSO, 2000.

RAZUMOVSKIY, D. Problemas de colonización agraria en los países de América Latina (con el ejemplo de Brasil y Argentina). Anuario Americanista Europeo, Paris, n. 6-7, p. 327-343, 2008-2009.

SALAMA, P. Pobreza e Exploração do Trabalho na América Latina. São Paulo: Boitempo, 2001.

SOTELO VALENCIA, A. América Latina: de crisis y paradigmas - la teoría de la dependencia en el siglo XX. México: Plaza y Valdés, 2005.

NOTA

1 Para uma dimensão analítica atualizada sobre a grilagem em América Latina recorrer ao artigo de Borras Jr; Kay; Gómes e Wilkinson (2012), que sistematizam dados de pesquisa financiada pela FAO (sigla em inglês para a Organização das Nações Unidas para Alimentação e Agricultura). 


\section{Guillermo Alfredo Johnson}

Psicólogo

Doutor em Sociologia pela Universidade Federal de Santa Catarina (UFSC)

Professor Adjunto da Universidade Federal da Grande Dourados (UFGD)

E-mail: guijohnson@uol.com.br

\section{Marcos Antônio da Silva}

Cientista Social

Doutorado em Integração da América Latina

Professor de Ciência Política da Universidade Federal da

Grande Dourados (UFGD)

E-mail: marocam@terra.com.br

\section{Universidade Federal da Grande Dourados - UFGD}

Faculdade de Ciências Humanas.

AC Dourados

Jardim América

79804970 - Dourados, MS 